\title{
Governança Da Água E Os Elementos Essenciais Para Prevenir Crises Planetárias: O Caso Brasileiro
}

José Irivaldo Alves Oliveira Silva*

Universiadade Federal de Campina Grande, Unidade Acadêmica de Ciências Sociais, Campina GrandePB, Brasil.

iD https://orcid.org/0000-0002-0022-3090

Resumo: A Covid 19 coloca na pauta planetária a nossa capacidade de tratar articuladamente os problemas sistêmi-cos que possuímos como meio ambiente e, especialmente, a água. Dessa, forma nos inquieta a seguinte questão: como lidaremos com as questões hídrico-ambientais no pós-pandemia utilizando princípios de governança com base numa matriz ecológica? Desejamos pensar num encaminhamento mais pragmático de modo a refletir numa perspectiva para as próximas décadas que virão e que poderemos ser surpreendi-dos por novas pandemias mas estando melhor preparados. Portanto, por meio da análise bibliográfica contemporânea e clássica, além do estudo documental e da legislação acerca da governança hídrica reali-zamos pesquisa que resultou nesse ensaio. Portanto, pudemos constatar que é possível uma mudança de paradigma, no entanto, isso só será viável com um modelo de governança adaptativa que tenha na sua base a participação de todos os setores envolvidos e a tomada de decisão com fundamento numa matriz ecológica.

Palavras-chave: Pandemia. Saneamento. Governança. Água.

\footnotetext{
* Doutor em Ciências Sociais. Doutor em Ciências Jurídicas. Professor do curso de Gestão Pública da Universidade Federal de Campina Grande, Ciência Sociais e Educação do Campo, no Centro de Desenvolvimento Sustentável do Semi-árido (CDSA). E-mail: irivaldo.cdsa@gmail.com
}

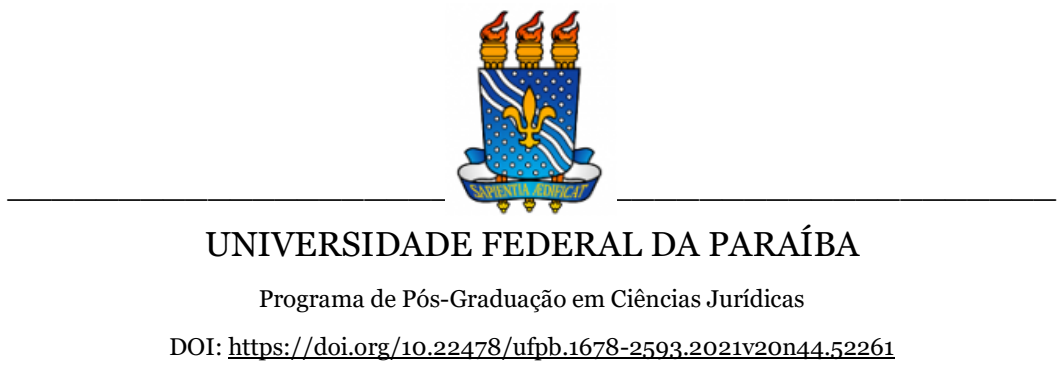




\title{
Governança Da Água $E$ Os Elementos Essenciais Para Prevenir Crises Planetárias: O Caso Brasileiro
}

\author{
José Irivaldo Alves Oliveira Silva
}

\section{INTRODUÇÃO}

Diante da importância da água como elemento de análise de múltiplas dimensões de uma nação, tais como: o nível de democracia de um país, o nível de cumprimento dos direitos humanos, o nível de poluição dos rios e outros mananciais, entre outros parâmetros; nos deparamos com a necessidade de voltarmos a pensar no tema da governança como essencial para a acomodação de interesses que divergem, uma vez que estamos tratando de um recurso comum, mas que nem todo mundo tem acesso. Considerando ainda a implementação de modelos de governança como a melhor forma de prevenir, mitigar e sair de uma crise, como a pandemia da Covid 19 por exemplo, cuja principal profilaxia é o acesso à água e à higiene básica no cotidiano, precisamos pensar em formas de nos preparar melhor para futuros eventos críticos como esse.

Partimos da premissa de que há uma crise ambiental e para além dela, há uma crise hídrico-sanitária com causas provenientes da própria dinâmica da natureza e estruturais originadas, certamente, dos modelos de desenvolvimento adotados pelos governos, embora ainda se classifique como crise hídrica ou crise da água separadamente, considerando que ainda temos milhões de pessoas sem acesso à água potável tão pouco ao esgoto tratado, itens básicos para compor o que chamamos de vida digna. 
Desse modo um problema nos chama atenção, em pleno século 21: como lidaremos com as questões hídrico-ambientais no póspandemia utilizando princípios de governança com base na equidade e numa matriz ecológica? A governança é importante pois a ela foi dada a possibilidade de conferir coerência no processo de gestão da água, uma vez que é preciso fazer funcionar bem a gestão nessa seara porque dela dependerão a proteção à saúde e os múltiplos usos da água, especialmente no ciclo urbano, notadamente nas regiões metropolitanas, uma vez que temos diversos territórios nos quais o uso será num modelo competitivo, sendo uma parte do volume captado e tratado para o setor produtivo, indústrias e agricultura, e outra parte, a menor delas, para os consumidores domésticos. Tudo isso deve ocorrer sobre um supraterritório, conhecido como bacia hidrográfica.

O nosso objetivo geral é analisar a governança como caminho factível para preparação da sociedade para momentos de crise, podendo mitigar ou prevenir seus efeitos. Não pretendemos apenas fazer um resgate da literatura sobre governança, o que não foi exaustivo, mas como objetivo específico constituir uma proposta principiológica que possa absorver as necessidades contemporâneas sob uma nova visão de um mundo que passa por transformações profundas, principalmente quando nos deparamos com mais uma pandemia que pode ser potencializada pela falta de saneamento básico, notadamente falta de água e esgoto tratado, o mínimo necessário para a sobrevivência saudável dos seres humanos e a qualquer outro tipo de vida na natureza. A pandemia está exercendo pressão para que pensemos num sistema alternativo.

Há diversas literaturas que abordam o tema da governança, mas nesse artigo desejamos pensar num encaminhamento mais pragmático de modo a pensar numa perspectiva para as próximas décadas que virão e que poderemos ser surpreendidos por novas pandemias mas já melhor preparados em itens básicos como o saneamento. Portanto, por meio da análise bibliográfica contemporânea e clássica e documental acerca da governança 
genericamente e especificamente da governança hídrica em nosso país e em outros Estados realizamos a presente pesquisa pautada no método indutivo. Portanto dividimos o artigo na demonstração de uma crise, passando pelo recorte teórico que fizemos da governança e discussão de suas características, adentrando na governança da água no Brasil, finalizando com as bases principiológicas ou de diretrizes de uma governança que entendemos como sendo potencialmente preparada para prevenir crises como as que estamos vivenciando.

\section{UM BREVE PANORAMA DA CRISE}

A crise da água tem elementos que advém necessariamente da racionalidade planificadora humana, que se transformou na principal razão da construção desse contexto crítico que se está vivenciando, não só em virtude da pandemia, que é uma consequência, mas por todo o processo de desconstrução da natureza. Entretanto, é possível perceber a ação humana sobre os corpos d'água e a implementação de um modo utilitarista de se relacionar com esse elemento fundamental para a sobrevivência planetária. Essa racionalidade molda o território, transformando o desenho de rios, de aquíferos, enfim, com impactos severos sobre as bacias hidrográficas em virtude da lógica do capital numa perspectiva hidrossocial (SWYNGEDOUW, 2009). Por isso, é ingênuo achar que a crise está dada, ela é muito mais construída do que efetivamente fruto de um resultado da dinâmica da natureza.

O relatório da UNICEF (Fundo das Nações Unidas para as Crianças) de 2017 demonstra dados que caracterizam essa crise como algo real, firmando uma concepção de crise no ciclo urbano da água, incluindo o saneamento básico como indicador desse processo deletério da dignidade humana e da qualidade ambiental (UNICEF, 2017).

Podem ser elencados algumas informações cruciais: (1) Muitos países carecem de dados sobre a qualidade dos serviços de água e 
saneamento. O relatório inclui estimativas para 96 países sobre água potável administrada de forma segura e 84 países com saneamento gerenciado de forma segura; (2) Nos países que enfrentam conflitos ou distúrbios, as crianças têm quatro vezes menos probabilidade de usar serviços básicos de água e são duas vezes menos propensas a usar os serviços básicos de saneamento do que crianças em outros países; (3) Existem grandes lacunas no serviço entre áreas urbanas e rurais. Duas em cada três pessoas com água potável gerenciada com segurança e três em cada cinco pessoas com serviços de saneamento gerenciados de forma segura vivem em áreas urbanas. Das 161 milhões de pessoas que utilizam águas superficiais não tratadas (de lagos, rios ou canais de irrigação), 150 milhões vivem em zonas rurais.

Há dúvidas se as metas dos Objetivos de Desenvolvimento Sustentável (ODS), especificamente a meta 6 da universalização da água potável, coleta e tratamento de esgoto até 2030, vão ser efetivamente cumpridas em países como o Brasil. Quando se analisa o Brasil em termos de bacias hidrográficas, notadamente como se dá o saneamento nesses espaços (figura 1), é possível perceber a ineficiência do ciclo urbano da água. Isso impacta diretamente sobre os mananciais superficiais e subterrâneos formados pelo ciclo natural da água. Portando, o dano potencial vai seguramente além do perímetro urbano, podendo atingir uma extensão maior.

Em áreas extremamente relevantes no contexto ambiental como a bacia amazônica, a bacia do Paraná e a bacia do São Francisco, a remoção da carga de esgoto não é eficiente comprometendo a potencialidade dos serviços ambientais fornecidos por essas bacias, em especial o fornecimento de água para as regiões metropolitanas, sem mencionar que as populações difusas, comunidades rurais em geral ficam à margem desse sistema, havendo uma exposição às doenças de veiculação hídrica, o que torna o sistema vulnerável às novas doenças como a Covid 19, cujos estudos estão avançando sobre a possibilidade de transmissão feco-oral (HELLER et al, 2020; ZHANG et al, 2020; SIDDAHARTA et al, 2017). 
A figura 1 demonstra que temos um saneamento ineficiente que lança esgoto bruto nas bacias hidrográficas de todo o país o que causa principalmente poluição cuja consequência é danosa tanto para a saúde dos habitantes da região como para a qualidade do meio ambiente e seus serviços ecossistêmicos. As consequências se espalham por múltiplos territórios, inclusive com impactos transnacionais considerando a existência de emissários submarinos que podem transportar esgoto não tratado para alto mar. O fluir da água transporta milhares de microorganismos e sedimentos que podem provocar uma contaminação sistêmica.

Figura 1 - Mapas apresentando a divisão do país em bacias hidrográficas e a eficiência do sistema de saneamento
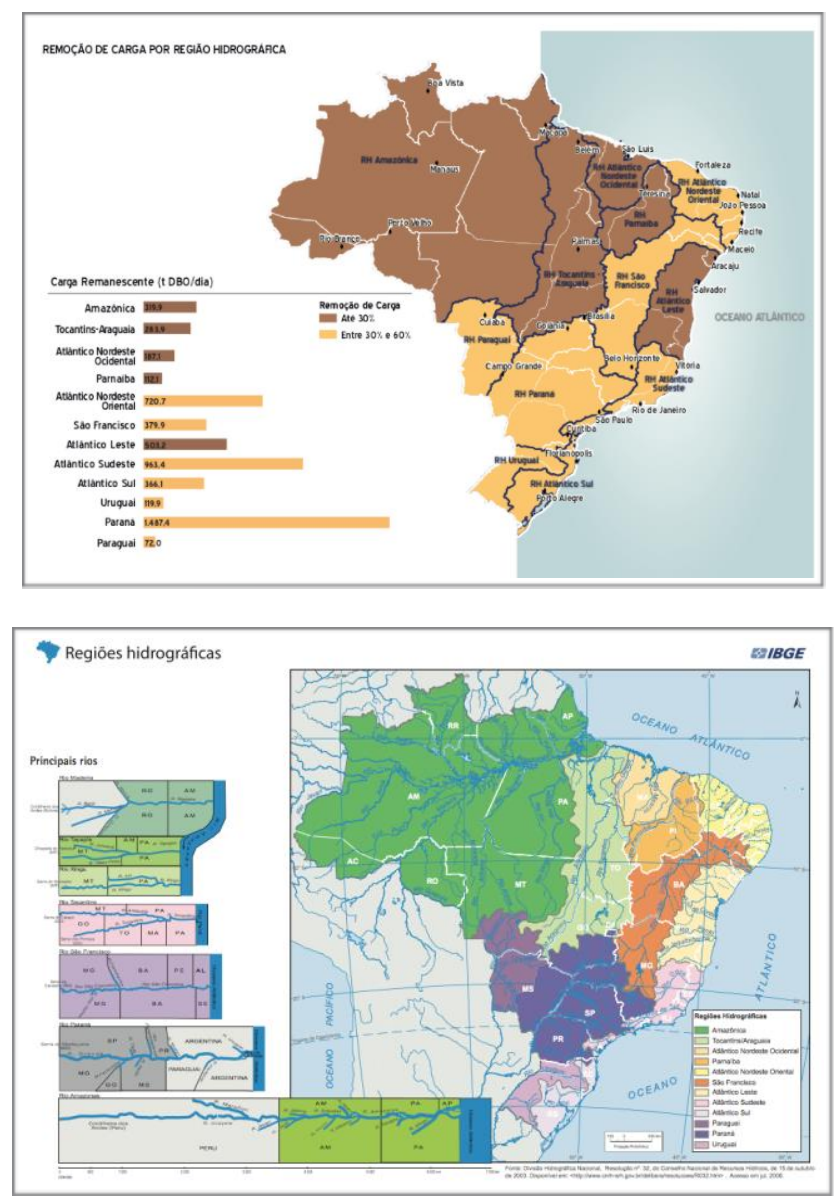

Fonte: Brasil, 2017;

https://atlasescolar.ibge.gov.br/images/atlas/mapas_brasil/brasil_bacias.pdf 
No caso brasileiro temos um panorama bastante ruim em processo de degradação. A figura 1 apresenta dois mapas cujas divisões político-administrativas estão inseridas numa subdivisão supraterritorial que a lei 9.433/1997 classifica como bacia hidrográfica, que é a unidade espacial básica para implementação da Política Nacional de Recursos Hídricos (PNRH) e a atuação do Sistema Nacional de Gerenciamento de Recursos Hídricos (SINGREH).

Portanto, nesse espaço temos a dimensão de uma tragédia em curso, predominando a baixa eficiência do saneamento e a alta potencialidade da poluição dos rios principais e afluentes dessas bacias, como o Rio Amazonas, no norte do país, o Rio São Francisco no nordeste e sudeste e o Rio Paraná, no Sul. Somos um país decantado pela vastidão de águas, rios caudalosos, porém, o binômio qualidade versus quantidade está ameaçado, pois num futuro não tão distante podemos ter quantidade mas não ter qualidade. (SILVA, 2020).

É importante afirmar que não se trata de um problema restrito ao Brasil, mas o mundo hoje reutiliza pouco a água, e as águas residuais são despejadas sem tratamento nos mananciais superficiais e nos aquíferos (UNESCO, 2019), o que indica a ineficiência dos ordenamentos jurídico ambientais para prevenir ou mitigar esses problemas (UNEP, 2019). Para nós isso indica um problema de governança muito mais estrutural e profundo que precisa ser debatido e caminhar para uma mudança de paradigma. Elementos como escassez, qualidade, mudanças climáticas e democracia estão relacionados com uma boa ou má governança. (JACOBI et al, 2017; SILVA, 2020).

\section{A GOVERNANÇA: PORQUE ELA É IMPORTANTE COMO PARTE DA SOLUÇÃO DA CRISE?}

Nesse contexto de crise, estudar a governança e seus pressupostos é fundamental. Ela é permeada principalmente pela 
atuação política do governo. A governança está presente em diversos setores da sociedade, inclusive nas corporações, sendo uma expressão muito comum na seara empresarial, até maior que no setor público, falando-se em "boa governança" ou "má governança" para caracterizar a organização do poder e seus resultados. Inclusive tem sido muito utilizada a expressão no campo das novas tecnologias e novos empreendimentos. (RAMALHO, 2019). Destaque-se que a governança estará suportada por diferentes valores conforme seja uma organização privada ou uma organização pública. Em ambos os casos, a governança implica no manejo de diversos fatores fundamentais para o fluxo decisório (CAPELLA, 2018).

Russel e Scott (2003) se baseiam na governança corporativa para compreendê-la, apontando para elementos como atores públicos e privados, recursos humanos, ordenamento jurídico, transparência, entre outros. Entretanto, nesse caso das corporações privadas o foco está nos resultados, expresso, geralmente, por rentabilidade. Foco em resultados não é ruim em si mesmo, mas dependerá de qual organização se está tratando. Essa é uma questão central em um ambiente financeirizado, como boa parte do planeta, em que a métrica disponível é justamente o quanto uma organização rende. Ademais, Rodrigues e Bernardo (2020) apontam a transformação dos modelos de governança mais verticalizados, cuja principal característica é a hierarquia, para um modelo mais flexível chamado "governação", mais horizontalizado e tendo a participação de atores que não são do circuito da política.

Segundo Meier e O’Toole (2011) a articulação de diversos fatores é fundamental para o fluxo de ações que circula no processo de governança, devendo ocorrer em forma de interações com foco no bem-estar da população. O que os autores destacam é justamente a governança na escassez de recursos e de crises buscando-se modelos que possam atuar mesmo nesse cenário. Segundo Seixas et al (2020) a governança ambiental, por exemplo, é um campo que tem uma grande multiplicidade de atores e cuja complexidade pode ser paradigmáticas para o enfrentamento das crises pós-modernas. 
O panorama de escassez de água é bem apropriado para se pensar em novos modelos de governança pautados em diretivas mais justas e ecológicas. Porém, não é uma compreensão uníssona. A Global Water Patnership (GWP), que atua no assessoramento de países para a implementação de modelos de governança de água, entende a governança como sendo caracteriza pelo exercício da autoridade econômica, política e administrativa na gerenciamento dos assuntos de um país em todos os planos (GWP, 2006). O Programa das Nações Unidas para o Desenvolvimento adota uma compreensão similar (UNDP, 1997).

Entretanto, é urgente pensar-se em paradigma mais atualizado de governança para auxiliar na implementação de fundamentos ecológicos em políticas públicas que, certamente, podem auxiliar a prevenir, mitigar e gerir crises. Entretanto Braga et al (2020) pontua que essa governança não pode ser confundida com a gestão, com o governo, ou mesmo com o poder político, sendo, na verdade, a estrutura para decidir quais serão as atividades de gestão dos recursos hídricos que serão implementadas, numa atmosfera de participação e maior democracia possível, uma vez que os atores locais e regionais estão mais cientes do que está acontecendo com a água em seus territórios e podem contribuir para uma melhor decisão.

É preciso trabalhar com diversos cenários em curto, médio e longo prazo. Parece que não há com consenso nesse debate em torno de um conceito único para governança. O termo 'governança' é aplicado em diversos contextos de tempo e espaço. Na literatura ocidental, é marcante a preocupação em torno da mudança entre o antigo governo e o sistema da Vestfália, que compreende o mundo dividido e organizado em estados-nação soberanos com territórios exclusivos, com o monopólio interno da força.

Inevitável comparar com a concepção de governo hierarquizado de "cima para baixo". Porém, mudando-se da leitura de governo para governança, o primeiro passa a ser mais um ator compondo a arena política. A arena como espaço de articulação e construção de 
entendimentos se torna mais movimentada, ficando as fronteiras entre a esfera pública e privada mais imprecisas (KENNETT, 2008). Paiva Sobrinho et al (2019) entendem que uma governança da água para está bem posicionada na contemporaneidade é fundamental mecanismos de transparência e de prevenção e combate à corrupção.

Um modelo linear de governança não se adequaria mais às diversas formas de organizações que existem, notadamente num contexto multiescalar como é no Brasil envolvendo entes federados, sociedade civil e todos inseridos numa outra escala de governança e gestão, a bacia hidrográfica. Os cenários são complexos e demandam modelos mais flexíveis que se adaptem às demandas do conjunto de atores envolvidos. O modelo centralizados dos estados já não responde mais adequadamente essas demandas diversas, especialmente quando a natureza e seus fatores então em jogo. Raadschelders, Vigoda-Gadot e Kisner (2015), em estudo amplo sobre a administração pública pelo mundo, admitem que e os poderes mais centrais tem perdido espaço, especificamente em políticas públicas tão complexas e difusas como água e saneamento, considerando ainda o impacto de novos movimentos nacionalistas que entra em colisão com um modelo de governança mais horizontal. O que se verifica é melhor performance de estruturas organizacionais que compreendem como articular os diversos fatores presentes.

Governança vai além do mero exercício de poder ou concentração do mesmo, na verdade, inclui estratégias e articulações, foco em resultados, produzindo modelos, traduzindo-se em formas como essa autoridade pode ser exercida em múltiplas escalas (FREY et $a l, 2019)$. Marks and Hooghe (2004, p. 15) classificam que a governança atualmente se apresenta como multiformas de exercício do poder.

A difusão de autoridade em novas formas políticas levou a uma profusão de novos termos: governança em vários níveis, governança em camadas, governança policêntrica, governança em múltiplas perspectivas, jurisdições funcionais, sobrepostas e concorrentes (FOCJ), 
fragmentação (ou esferas de autoridade) e consórcio e condomínio, para citar apenas alguns. (Tradução livre) ${ }^{1}$

Pereira (2011, p. 121) aponta a aplicabilidade dos pressupostos da governança privada ao ambiente público: "seria uma forma de transformar a complexidade desestruturada em uma complexidade estruturada, ainda que não se pudessem controlar os 'n' efeitos da simplificação e estruturação pretendidas”. A coesão do sistema é buscada pela governança. Tovar et al (2015, p. 577) declara que a governança propriamente dita tem as seguintes características, considerando sua multiplicidade de aplicações:

1. é o processo pelo qual os governos são selecionados, supervisionados; 2. é a capacidade do governo de formular e implementar políticas saudáveis de forma eficaz; e 3. é o respeito dos cidadãos e do Estado pelas instituições que governar as interações econômicas e sociais entre eles. (Tradução livre) ${ }^{2}$

Um conceito mais adequado de governança deve trazer como bases relacionados com autoridade, governo e jurídicos que vão orientar as regras do "jogo". Outrossim, apresenta também princípios de administração pública e de gestão pública, que servirão, por exemplo, para o desenvolvimento e implementação de políticas públicas. Entretanto, não é conveniente, como atesta Carini et al (2019), uma noção de governança exclusivamente centrada na autoridade, trazendo uma hierarquização que não ajuda no processo de participação e implementação de mudanças. O governo não é o elemento mais relevante no processo, é mais um que possui suas atribuições específicas. Na realidade, o como se procede e como se chega às finalidades de determinada política são elementos centrais

\footnotetext{
${ }^{1}$ The diffusion of authority in new political forms has led to a profusion of new terms: multi-level governance, multi-tiered governance, polycentric governance, multiperspectival governance, functional, overlapping, competing jurisdictions (FOCJ), fragmegration (or spheres of authority), and consortio and condominio, to name but a few.

2 1. es el proceso por el cual se seleccionan, son supervisados los gobiernos, 2. es la capacidad del gobierno de formular y de aplicar políticas sanas con eficacia, y 3. es el respeto de ciudadanos y el Estado para las instituciones que gobiernan las interacciones económicas y sociales entre ellas.
} 
em busca de uma governança com conteúdo significativo, que promova transformações na sociedade (CASTELLANOS, 2017). Portanto, em um contexto de relações sociais complexas se faz necessário um conceito mais holístico de governança.

Kooiman (1993) afirma que o pressuposto central a se levar em conta é que se está inserido em uma sociedade diversa, dinâmica e complexa e que, portanto, qualquer conceito de governança que se adota deve levar em consideração em seu escopo, para sua mínima eficácia, essas três dimensões. Assim, arremata-se e que, de forma geral, a definição de governança deverá considerar o que se pretende atingir, o grau de eficácia e de impacto na sociedade.

Busca-se um modelo de governança pública com finalidades muito específicas voltadas ao bem-estar da coletividade, com foco em políticas públicas, cuja racionalidade preponderante seja democrática baseada na participação e na construção de uma agenda pública pelo sistema político, sendo implementada e avaliada. (CAPELLA, 2018). Entretanto, concorda-se com Pires e Cavalcante (2018) que o significado de governança é fluido, constituindo-se numa oportunidade de governos adaptarem os arranjos como aqueles relacionados com a governança da água. O direito deve ser importante nesse processo, estabelecendo papéis muito claros de todos os atores, as regras do "jogo", dando segurança jurídica aos processos entabulados limitando as "vontades" dos governantes, buscando-se um mecanismo de controle social e jurídico eficaz das políticas públicas (BARREIRO et al, 2015; CUNHA et al, 2017). Nesse diapasão, a política de água e saneamento são políticas fundamentais e que podem ser uma seara fértil para se testar e implementar novos modelos participativos de governança.

\subsection{Diretrizes para uma governança da água}

$\mathrm{Na}$ seção anterior verificaram-se as principais facetas da governança, suas contradições e possibilidades de aprimoramento. 
Entretanto, ficou patente que em um cenário de crise e de problemas hipercomplexos é fundamental ter-se um modelo de governança dotado de mecanismos que possam lidar com essas questões de natureza pública. Aqui será abordada a gestão da água, pensando a partir de um enfoque mais ecológico que norteará o planejamento de forma mais holística de modo a dotar as organizações e instituições de uma resiliência fundamental para passar pro momentos de crise como a atual pandemia, provavelmente advinda da relação homem e natureza.

Nesta análise é pressuposto ter-se uma legislação inspirada em arranjos sistêmicos, ou seja, partindo da interdependência de diversos fatores que formam o planeta, reconhecendo os fenômenos como eles são, a exemplo do ciclo da água que na sua essência é produto de um sistema que funciona a partir dessa interdependência de modo a amparar o mínimo necessário para o consumo humano e a manutenção dos ecossistemas. A água por si só é um bem ambiental peculiar em virtude de suas características intrínsecas, sua limitação superficial e subterrânea, e seu caráter de ser um direito humano dependente de um ciclo natural frágil que necessita do mínimo equilíbrio possível possibilitado principalmente pela ação humana que, entretanto, tem sido no sentido de poluir corpos d’água e depreciar as bacias hidrográficas (PACHECO-VEGA, 2014).

Tratar da governança da água aponta para elementos de complexidade em si: a água é um recurso comum, do qual toda forma de vida depende para sobreviver, sendo essencial a ação de diversos atores para que seus múltiplos usos sejam regulados através de uma atuação institucional e coletiva. Ostrom et al (1994) apresentam que recursos como a água sofrem do problema da Common-pool (recurso comum), uma vez que existe a possibilidade concreta de uma exploração excessiva demandando um controle.

Para Ostrom (1999, p. 493) são três os pontos essenciais para que haja a implementação de uma análise institucional atualizada de governança da água e que pode servir de background teórico nesse 
campo, mas que não esgotam as possibilidades de análise: (a) os usuários são um dos problemas, uma vez que eles tendem a não cooperarem entre si de modo a superar e resolver os dilemas comuns compartilhados, ou seja, há uma tendência de maximização de ganhos; (b) talvez seja uma tarefa analítica simples projetar regras que visem transformar formas de incentivo entre os participantes; e (c) seria necessária uma organização centralizada.

Para Elionor Ostrom (1999), há limites estabelecidos para todos os processos de tomada de decisão. A discussão no âmbito da governança deve incluir os limites em suas várias dimensões e acepções, considerando a possibilidade concreta de criar diversos centros de decisão, um verdadeiro sistema policêntrico, combinando os pontos fortes no processo de resolução de conflitos, inevitáveis em qualquer sistema, além da necessidade de aquisição de conhecimento científico, buscando o monitoramento do desempenho de sistemas locais acompanhado da regulamentação de recursos comuns. Esses sistemas policêntricos devem ser necessariamente sistemas adaptativos complexos, o que possibilitaria uma amplitude de análise e de visão sobre a organização acerca do uso de bens comuns como a água, incluindo-se outras questões que possuam a mesma natureza constitutiva. Parece que uma governança efetiva da água começaria a partir dessa mudança de concepção.

É possível perceber que há adequação da teoria dos recursos comuns de Ostrom à governança dos cursos de água, superficiais e subterrâneas, considerando que nesse processo é muito difícil excluir usuários. Além dos usuários convencionais, os free riders podem superexplorar o recurso trazendo prejuízos (OSTROM et al, 1994). São diversas as situações que podem ser contempladas por esses estudos. Ostrom (1999, p. 493) identificou elementos similares na totalidade de situações abordadas, tais como: 1) participantes; 2) posições; 3) ações; 4) resultados; 5) transformação em funções que liguem ações a resultados; 6) informações; e 7) recompensas (incluindo tanto retornos positivos como sanções negativas quando relevantes). 
A governança da água expressa a complexidade das relações sociais em espaços específicos ou arenas políticas como a destinada à gestão, por exemplo. (OSTROM, 2005). A institucionalidade prepondera nessa seara em que se encerra nela própria diversas interrelações, das quais as vidas no planeta dependem para sobrevivência. Ostrom pontua a influência do comportamento humano pelas instituições, fato presente na governança ambiental. As expectativas são diversas, porém nem todas se concretizam diante do “jogo" procedido no âmbito dessas instituições.

Tanto na gestão da água como no saneamento faz parte da essência desse processo a participação de diversos atores, que são interessados, que compõem o sistema de governança da água,. Considerando o caso de uma crise pandêmica, como esta que se vivencia, é fundamental um olhar da governança da água para a saúde como dimensão interligada à qualidade ambiental e da água o que poderá se refletir nas decisões tanto da Administração Pública como do Judiciário. Entende-se que a governança da água tem preponderância em face dos demais sistemas relacionados, a exemplo do saneamento, uma vez que esse se deriva do primeiro. $\mathrm{O}$ ciclo natural da água em conjunto com o ciclo urbano da água devem ser a prioridade dessa governança.

Ostrom traz os modelos policêntrico como sendo uma solução para sistemas complexos como o da governança da água, que demandam diversos centros de decisão, um verdadeiro sistema multinível. Esses setores tendem a uma direção autônoma, que não implicam necessariamente num resultado caótico (OSTROM, 2010). A governança da água, mesmo em contextos de maior centralização das decisões, a exemplo do norte americano e do israelense, é formado por um comendo multiescalar. Portanto, a governança policêntrica é fundamental para a gestão da água.

A água está disposta de forma livre na natureza, em rios, aquíferos, lagos e mares. Porém, essa reserva acaba por ser apropriada para a execução de múltiplas funções, como consumo humano e 
atividades econômicas em geral. Nesse diapasão, cabe ao poder público a fiscalização desses usos, mediante um planejamento específico com base nas diretrizes da governança. Daí, surge o grande problema para uma governança policêntrica da água, sustentar o modo de vida dos aglomerados urbanos, especialmente as necessidades dos sistemas econômicos que se apropriam desse precioso líquido. Essa equação traz elementos que se coadunam com os problemas apontados na teoria de Ostrom, grande quantidade e diversidade de usuários e aplicações. Ostrom (1999, p. 515) afirma o seguinte:

Durante a estação mais abundante, por exemplo, os irrigadores podem ser autorizados a levar água sempre que necessário. Durante uma temporada em que a disponibilidade de água é moderada, os agricultores podem usar um sistema de rotação no qual todo agricultor está autorizado a tomar água por um período fixo de tempo durante a semana, com base na quantidade de terra a ser irrigada. Durante a escassez, o sistema de irrigação pode empregar um distribuidor especial de água que esteja autorizado a alocar água para os agricultores que cultivam culturas autorizadas pelo sistema de irrigação e que mais necessitam. (Tradução livre). 3

A questão crucial para a governança pública da água é elaborar estratégias de distribuição justa entre os usuários, com destaque para os ecossistemas, que também precisam dessa água. A governança da água vai além de um modelo de governabilidade, com se pode constatar até aqui (GWP, 2013; MORAES e LICEA, 2013). Entretanto, há um aspecto que precisa ser contabilizado, o planejamento hídrico ou a planificação de projetos hídricos, ou seja, democraticamente decidir acerca dos múltiplos usos da água.

Dentre os parâmetro utilizados para medir a boa governança da água, está a universalização, que precisa ser atingida como forma de concretização da dignidade humana. Essa é pautada pela distribuição

\footnotetext{
3 During the most abundant season, for example, irrigators may be authorized to take water whenever they need it. During a season when water availability is moderate, farmers may use a rota- tion system in which every farmer is authorized to take water for a fixed amount of time during the week based on the amount of land to be irrigated. During scarcity, the irrigation system may employ a special water distributor who is authorized to allocate water to those farmers who are growing crops authorized by the irrigation system and are most in need.
} 
equânime da água para todos, não sendo razoável que existam bilhões de pessoas que ainda não possuem acesso à água (UNESCO, 2006). Problemas relacionados à água ocorrem em diversos países, por exemplo, que possuem distorções na governabilidade, caracterizadas pela limitação de direitos individuais e liberdade. Para que isso mude, é fundamental o trabalho em colaboração e envolvimento de atores interessados para que qualquer política pública hídrica funcione minimamente; fazer com que a maioria dos países possam atingir um nível razoável de implementação da política; pensar em reformas na gestão da água quando necessárias; produzir mecanismos que previnam processos de corrupção; fazer-se compreender que a governança está relacionada aos arranjos políticos e de poder; e considerar modelos alternativos e adaptativos de governança, primando pela autonomia das comunidades, considerando que não há uma forma que se adeque a todas as situações. Destaque-se o seguinte:

É importante desenvolver instituições e sistemas de governança que possam responder efetivamente a situações caracterizadas por variabilidade, risco, incertezas e mudanças. O planejamento convencional da água permanece rígido e o desafio continua a desenvolver estruturas e instituições de governança adaptáveis. É necessário dar mais atenção às instituições e abordagens resilientes que possam governar ou orientar o processo complexo e cheio de surpresas da governança da água, central para a gestão de longo prazo nos níveis regional, de bacia, aqǘf́ero e local.(Tradução livre). (UNESCO, 2006, p. 9) 4

A palavra "adaptação" terá um caráter especial no âmbito da governança, tendo em vista com contexto de mudanças e limitações de recursos. O relatório da UNESCO (2006) mencionada a gestão integrada da água como objetivo central e responsabilidade a ser concretizada por instrumentos institucionais e jurídicos apropriados. O relatório de 2019 (UNEP, 2019) apresenta uma análise mais

4 important to develop institutions and governance systems that can respond effectively to situations characterized by variability, risk, uncertainties and change. Conventional water planning remains rigid and the challenge remains to develop adaptive governance frameworks and institutions. More attention needs to be given to resilient institutions and approaches that can govern or guide the complex, surprise-laden process of water governance central to long-term management at regional, basin, aquifer and local levels. 
específica e aprofundada acerca do acesso à água e saneamento, apresentando-se temáticas novíssimas como o que trata dos refugiados da escassez, ou seja, pessoas que saem do seu território em busca de melhores condições ambientais, especialmente água e alimento.

Com base no referido relatório, é possível elencar traços de uma boa governança: (1) Uma governança adequada precisa satisfazer a alguns critérios compostos por responsabilidade, transparência, legitimidade, participação do público, justiça e eficiência e, portanto, se aproximam de uma abordagem baseada nos direitos humanos (human rights-based approach). (Tradução livre).5 (p. 4); (2) Essa boa governança precisa ser permeada por instrumentos proativos que garantam a eficácia, apresentando responsabilização com o desempenho inadequado, alguma ilegalidade ou abuso de poder. (Tradução livre) ${ }^{6}$ (p. 82); (3) Como já mencionado, para o bom funcionamento da governança da água não favorece estruturas hierárquicas de poder, mas sim uma horizontalidade maior. (Tradução livre). 7 (p. 151); (4) Uma governança bem conduzida ela atua positivamente sobre a política pública de água, lembrando que os impactos negativos da corrupção precisam ser mitigados e eliminados. (Tradução livre) $^{8}$ (p. 9o); (5) A capacitação das comunidades mais vulneráveis é crucial para uma política da água adequadamente implementada. (Tradução livre) ${ }^{9}$ (p.158);

Os estudos acerca da governança indicam que há a necessidade de concentrar esforços na busca da estabilização das situações de conflito, uma vez que eles existem em todo esse processo. Entretanto,

5 Good governance relates to systems that have qualities of accountability, transparency, legitimacy, public participation, justice and efficiency and therefore overlaps with the principles of the HRBA.

${ }^{6}$ Good water governance involves pro-active measures and mechanisms, ensuring guidance towards effective implementation along with sanctions against poor performance, illegal acts and abuses of power.

7 Seeks to move away from hierarchical power structures.

8 The positive impact of good governance (and the negative impact of corruption) has been proved to affect the efficiency of water utilities.

9 Empower the most disadvantaged groups - is essential for successful implementation of water policies. 
o difusionismo da própria noção de governança aponta para o contexto da realidade, que definirá como devemos agir no caso da governança da água (GOMIDE e SILVA, 2009; KATSAMUNSKA, 2016).

Dessa forma é possível asseverar que a gestão da água engloba o processo de governança de interesses dos atores implicados na utilização da água, desde a captação no ciclo natural da água, considerando a construção de infraestruturas para o ciclo urbano da água, e para o abastecimento difuso de comunidades rurais, permitindo-se um arranjo institucional que possibilite decisões que contem com a participação plena dos usuários. Uma coordenação do processo é necessária, de modo que as várias arenas possam estar num contexto de menor conflito e maior simetria possível. Isso inclui momentos de pandemia como Covid 19, cuja prevenção mais eficaz não prescinde da água, que é fundamental para a higiene básica e que pode evitar a disseminação do vírus.

\section{UM NOVO PARADIGMA DE GOVERNANÇA DA ÁGUA}

É preciso pensar em como desenhar um modelo de governança da água diante de sua relevância basilar, considerando a importância da participação de todos os interessados e implicados no uso e acesso diário a esse líquido vital. Portando, é preciso pensar em como acomodar interesses díspares e assimétricos na medida do possível, sendo o direito uma importante ferramenta (SILVA e LEITE, 2019; LEITE e SILVA, 2019). Essa participação precisa ser qualificada para que se privilegie um modelo de governança adaptativa moldado às peculiaridades regionais. É destacável a importância de uma flexibilidade multinível com base territorial nas bacias hidrográficas, tendo um caráter socioambiental e jurídico.

O fato do acesso à água ser considerado como direito humano precisa ser estruturante nesse modelo de governança da água. Porém, 
é fundamental pensar-se de que modo seria encarado esse direito humano? Pensa-se que a melhor maneira seria desde uma releitura baseada em uma matriz ecológica. Desta feita, pensar numa matriz discursiva em 5 níveis de aplicação:

(1) Como direito humano: A Constituição Federal brasileira centra-se no princípio da dignidade humana, que deve ser a chave de leitura de todos os direitos fundamentais e sociais insculpidos em seu texto. Apesar de não se adotar claramente o direito humano à água em dezenas de países, em cartas políticas como a brasileira, mais principiológica e programática, é possível extrair esse direito do seu texto;

(2) Como Direito Ambiental: a água é o sustentáculo dos ecossistemas, sua base, bem como o suporte necessário para a concretização de um desenvolvimento sustentável. O desenho legislativo deve caminhar na direção da proteção da natureza que propiciará a proteção do ciclo natura da água, ou seja, da produção da água;

(3) Como Direito Administrativo: a água como elemento chave da gestão dos recursos hídricos, o que acaba por limitar muitas vezes a compreensão acerca dos múltiplos usos da água, ficando mais restrito ao ciclo urbano, sendo mais referenciado em face do investimento em estruturas hídricas que distribuem água para os usos mais urbanos. Faz parte dessa visão, a institucionalidade que compõe a governança da água;

(4) Como um nível essencialmente econômico: essa é uma compreensão bem mais restritiva que vai de encontro com a visão que se busca imprimir neste ensaio. Pensa-se a água, a partir dela, como sendo um bem econômico, sendo um instrumento da gestão que pode ser valorado, cujo principal instrumento de governança seria a cobrança como fonte de financiamento e limitação à exploração. Porém, essa visão econômica necessita ser dosada junto à compreensão da água como direito humano e ambiental e, por isso, deve-se-ia encará-la de maneira diferenciada; 
(5) Como um nível substancialmente da engenharia: nesse ponto, os problemas relacionados à água podem ser delimitados a uma questão meramente tecnológica de forma contrária a uma visão mais holística que inclui que as soluções devem considerar uma matriz ecológica e social. A engenharia providenciaria soluções tecnológicas que resolveriam o problema da escassez de água. Porém, tem-se uma questão eminentemente política que se refere ao acesso à água, visto que muitas vezes tem-se represas, transposições e outras soluções tecnológicas de engenharia, mas a população ainda padece sem água, a exemplo das comunidades rurais ao longo da transposição, e as comunidades rurais em todo o país que não são incluídas na solução do acesso à água e, também, saneamento.

Essa direção mais ecológica do direito humano à água deve se basear em uma perspectiva da ecologização dos direitos humanos, que poderá preparar o “terreno” para a resiliência e prevenção em face de endemias e pandemias que estão presentes e que virão, processo baseado na ressignificação do humano, como defendido por CavedonCapdeville (2018): (1) É preciso lembra da releitura que os direitos humanos auxiliam a fazer no processo de desconstrução de ideias tecnicista, reducionistas e mercantilistas que ainda permeiam o direito ambiental, dando elementos para sua reestruturação do direito ecológico, sendo um direito essencialmente da natureza; (2) O papel dos tribunais nos países, bem como as cortes internacionais com foco nos direitos humanos, cumprem um papel de transformação na jurisprudência ambiental apontando para a essencialidade da natureza no âmbito do desenvolvimento humano; (3) Urge a necessidade do resgate do simbolismo e da juridicidade dos direitos humanos no contexto desta crise, buscando sua releitura e concretização para proteção de seus titulares, de forma individual e coletiva, numa sinergia com o ambiente em que esses direitos devam se realizar; (4) Passa-se a um patamar de proteção não só dos titulares mas do ambiente em si, em uma perspectiva ecológica, considerando o frágil equilíbrio entre os membros de toda a comunidade planetária 
e de suas diferentes formas de interação; (5) É preciso aprimorar a comunicação do sistema jurídico-ambiental com os direitos humanos. Eles se retroalimentam, possuem sinergia entre si, o que fica mais claro em questões básicas como o acesso à água e ao saneamento, tendo-se uma violação clara a um direito humano, que pode ser melhor compreendido em termos das repercussões ambientais e sua interação com a qualidade de vida das pessoas, dos ecossistemas e a sobrevivência; (6) É preciso ressignificar a base ética a uma força simbólica que, articulados em novas dimensões de direitos ecologizados, que podem contribuir para construir, no âmbito do jurídico, uma nova visão de mundo centrada na Terra e na dignidade da comunidade planetária.

Entretanto, dentre os problemas que já existem, o principal deles é o formato da política de águas que se entende como top down (de cima para baixo). Dessa forma, é seminal que se transforme e se consolide numa política botton up (de baixo para cima). A multiplicidade de necessidade pressiona por multiplicidade de soluções. Além disso, é preciso reforçar a atuação dos comitês de bacia, que são a base do sistema de governança da água. (CARLI e VASCONCELOS, 2018).

\subsection{O modelo Brasileiro}

É preciso dizer que o nosso modelo participativo bottom up baseou-se no modelo francês, inclusive quanto aos conceitos de bacia hidrográfica e comitês de bacia e suas funcionalidades no sistema, portando, o sistema francês foi paradigmático. (BRAGA e ARGOLLO FERRÃO, 2015; FERRAÇO, 2019).

Podemos considerar que a governança da água no Brasil foi verdadeiramente institucionalizada e sistematizada a partir de 1997 com a lei que estabeleceu a Política Nacional de Recursos Hídricos (PNRH), n. 9.433, que também estruturou um Sistema Nacional de Gerenciamento Hídrico (SIGREH), que tem em sua base foco na 
Governança Da Água E Os Elementos Essenciais Para Prevenir Crises...

participação dos usuários através dos comitês de bacia. Essa política pública essencial para o desenvolvimento de todas as atividades em território nacional, é fundamentada em alguns princípios, quais sejam (art. 1, Lei 9.433/1997):

(1) A água é de domínio público: o que significa a essencial e estratégica importância desse líquido vital à coletividade. Portanto, está sob os auspícios do Estado tratar da sua gestão no contexto do SIGREH;

(2) A água possui valor econômico ou tem conteúdo econômico: significa que a água apesar de ser de domínio público não lhe é restringida a cobrança pelo acesso em virtude dos sistemas ou infraestruturas hídricas formados por adutoras, reservatórios, bombeamentos, estações elevatórias, plantas de tratamento, entre outros instrumentos que a tecnologia dispõe para a água chegar ao seu destino, notadamente nas regiões metropolitanas;

(3) Reconhecimento da limitação desse bem: a água é uma dádiva originada no processo cíclico na atmosfera e utilizada de forma racional por todos, transformando-se em recurso, principalmente quando mudamos nosso modo de vida essencialmente agrícola para uma vida fundamentalmente urbana dependente da água bombeada dos reservatórios construídos pela engenharia humana. Porém, o legislador na esteira da limitação dos bens ambientais renováveis compreendeu que o texto legal deveria explicitar o reconhecimento da limitação da água no mesmo item que estabeleceu que a água tem valor econômico, inserindo essa constatação de limitação no contexto de aumento de demanda e diminuição dos estoques da água, portanto, tornando-se mais rara, sendo um princípio basilar para pensar toda a governança da água estabelecendo uso racionalizado buscando sempre a economia e a reutilização;

(4) A prioridade da vida humana e a dessedentação de animais: esse fundamento estabelece a priorização da sobrevivência humana e, numa interpretação mais extensiva, dos ecossistemas, apesar de mencionar animais numa dicção mais restritiva, salvo 
melhor juízo, pensamos que a interpretação dos tomadores de decisão na seara jurídica deva apontar para uma ampliação desse princípio, ou seja, a vida está acima das demais atividades humanas, o que significa ainda concluir que numa situação de escassez, de falta de água, e o necessário estabelecimento de racionamento, ou seja, restrição de acesso e uso desse recurso, a vida deve ser priorizada, numa concordância explícita com o art. 5 da nossa Constituição Federal de 1988;

(5) A gestão que prioriza os múltiplos usos da água: a governança da água torna-se mais complexa do que qualquer outra, certamente por que envolve diversos interesses que podem ser, e geralmente são, opostos. Entretanto, os esforços da gestão, materializados numa governança transparente e participativa, devem ser no sentido de mediar esses interesses, uma vez que se utiliza a água essencialmente em quase todas as atividades humanas, principalmente na produção de alimentos na agricultura, que é seu maior uso, na indústria e no âmbito doméstico, dentre outras aplicações. Portanto, uma boa gestão seria aquela que consegue conciliar a manutenção de todos os usos ou, pelo menos os mais prioritários na perspectiva constitucional e da lei;

(6) A bacia hidrográfica deve ser a unidade territorial para implementação da PNRH e atuação do SIGREH: do ponto de vista do planejamento urbano ambiental consideramos que essa diretiva seja a mais importante, uma vez que os documentos internacionais acerca da gestão de águas tem por base essa unidade, que além de ser uma unidade territorial, geograficamente demarcada e posicionada, é aí que a governança através da gestão ocorre de fato e de direito. Dessa forma, o legislador estabeleceu essa unidade territorial como sendo o centro da gestão de recursos hídricos, sendo objeto de implementação da política pública através de instrumentos previstos em lei e que devem ser implementados e monitorados pelo SIGREH;

(7) A descentralização participativa da gestão: esse princípio também possui uma relevância estratégica para a 
Governança Da Água E Os Elementos Essenciais Para Prevenir Crises...

governança, uma vez que se reconhece as limitações de uma gestão centralizada, uma vez que estamos tratando de uma tarefa extremamente complexa dado o envolvimento de atores privados e públicos de diversas esferas, o que pressupõe interesses diversos que necessitam ser mediados. Dessa forma, os usos múltiplos da água acabam por se adequar mais a um modelo descentralizado e participativo, o que significa que usuários e comunidades, assim como o setor privado e público, devem estar contemplados no SINGREH.

O diploma legal que instituiu a PNRH estabelece as diretrizes de uma governança da água e, considerando o ano de sua entrada em vigor, cinco anos depois da Eco 92, no Rio de Janeiro, ela veio influenciada pelos valores discutidos nessa conferência internacional do meio ambiente, prevendo objetivos para serem aplicados na implementação da política, dentre esses podemos destacar: o direito intergeracional à disponibilidade de água de qualidade para as atuais e futuras gerações e seus respectivos usos; sem descuidar de um uso racional e integrado, considerando a mobilidade aquaviária, embora desnecessário, uma vez que o transporte é um dos múltiplos usos da água; dedicou também espaço para estabelecer a importância de se levar em consideração a prevenção e a defesa contra eventos hidrológicos extremos, seja por causas naturais ou por fatores advindos da intervenção humana e finaliza os objetivos destacando a importância de se incentivar a captação e uso das águas pluviais.

Em nossa compreensão, um detalhe chama a atenção no tocante às caraterísticas essenciais para a governança da água no Brasil, a necessidade de integração de forma explícita na legislação, o que obriga necessariamente a se ter uma visão sistêmica do todo da PNRH e do SINGREH, permitindo-se, dessa forma, planejar melhor os múltiplos usos, considerando-se que temos, também, múltiplas fontes de água, superficiais, subterrâneas, daí advindas de lagos, de rios, dos aquíferos, das represas, do mar e não esquecendo das águas residuais, ou seja, as que já foram utilizadas e podem ser reutilizadas. 
Essa característica remete à visão de uma só água produzida pelo ciclo hidrológico, ou seja, uma água que circula, que é produzida pela dinâmica circular das várias formas de água na atmosfera. Portanto, é preciso ter uma governança pautada numa clareza das fontes de água que temos, os usos que são feitos, a qualidade da mesma, a mitigação e até eliminação de perdas no sistema, e uma visão circular dessa água, ou seja, a noção de que a partir da produção da mesma pelo ciclo da água, ela ao entrar no ciclo urbano precisa ser considerada na sua dimensão de reutilização, claro que monitorando os seus indicadores de qualidade e as finalidades de uso da mesma, uma vez que os parâmetros mudam entre a água utilizada para consumo humano e dos ecossistemas e a utilizada para a agricultura e indústria, por exemplo.

Para além desses fundamentos objetivos estabelecidos pela lei é importante dizer que a nossa Carta Magna estabeleceu outros princípios para a administração pública, previstos em seu art. 37, que se aplicam claramente à gestão e governança das águas, uma vez que não estamos a falar de um conjunto de ações que formam uma política pública que se isola de outros ramos do Direito consolidado como o Direito Administrativo e o Direito Ambiental. Na verdade, um novo ramo do direito vem a se constituir como Direito da Água, mas num viés normativo interdisciplinar, considerando uma visão sistêmica mais aperfeiçoada.

Carli (2017) aponta uma subdivisão interessante sobre a água. Para ela temos: Direito à água, Direito das águas e Direito de águas. A primeira faz uma referência ao direito humano à água para sobrevivência da espécie. A segunda se refere à possibilidade de reconhecer a personalidade jurídica dos corpos d'água, de rios, mares, aquíferos diante de sua extrema relevância ecossistêmica e da possibilidade de conferir maior proteção. $\mathrm{E}$ a terceira subdivisão é a organização de um ramo do direito que trata da sistematização do gerenciamento de águas, abrangendo a governança e todas as normas que tratam do acesso e disponibilização da água e do saneamento. 
Como se trata de um sistema baseado na participação de diversos atores com interesses múltiplos, devemos destacar um princípio fundamental para estruturar um sistema de governança da água, que é a transparência. Como mencionado, a publicidade e transparência já estão no rol de princípios da administração pública, o que foi reforçado e detalhado em 2011 com a lei que dispunha sobre o Acesso à Informação, Lei Complementar n. 131 de 2009, que complementa a Lei n. 101 com relação à disponibilização de informações dos órgãos públicos referentes às finanças públicas. (JACOBI et al, 2014).

Portanto, claro que a PNRH deve ser encarada como uma lei base do sistema, porém, não impede que se complemente esse microssistema jurídico de governança com outras normas. Essas leis instrumentalizam a administração pública e a população no sentido de cobrarem de seus órgãos as informações necessárias que poderão fundamentar a tomada de decisão dos partícipes do processo de governança da água. Certamente partimos do pressuposto básico de que se torna praticamente inviável a tomada de decisão na governança da água se não houver informações de fácil acesso, disponíveis para a população.

Portanto, o Direto à informação do qual se origina o princípio da transparência e publicidade, é basilar para o funcionamento do sistema, conforme o Índice de Transparência em Manejo da Água (INTRAG) conforme estudo de Jacobi et al (2014) que demonstra a insipiência da aplicação desse princípio na governança brasileira, demonstrando que as regiões, como a norte, que possuem uma importante bacia hidrográfica tem baixa transparência no sistema o que indicaria uma governança débil, uma vez que não há informações qualificadas disponíveis.

O Brasil também teve sua governança da água influenciada por documentos normativos internacionais, advindos de conferências de meio ambiente ou mais específicas em relação à gestão de recursos hídricos. Ao longo do tempo formou-se um arcabouço jurídico 
internacionalio, incorporado ao Direito Internacional Público, que tratou especificamente de estabelecer um conjunto de instrumentos e princípios no sentido de fortalecer a governança da água entre nações uma vez que boa parte das águas do Planeta são compartilhadas e, considerando o princípio de unicidade de gestão, precisam ter harmonia normativa na governança de um recurso que é comum e perpassa nações distintas.

Essa governança também tem algumas diretrizes que precisam ser também levadas em consideração. O legislador classificou como "diretrizes gerais da ação", que a implementação do conjunto de ações da política pública de águas deve perseguir. A primeira dela diz respeito à necessidade de uma gestão que concilie quantidade e qualidade, todo o sistema de governança de águas deve buscar um equilíbrio nesse binômio. Esse é um ponto que direciona para uma reflexão mais profunda acerca da efetividade de nosso ordenamento jurídico na sua função de tutelar ou proteger os bens ambientais essenciais para a vida, uma vez que é necessário monitorar esses dois fatores, quantidade e qualidade, de modo que tenhamos a água em quantidade para os seus múltiplos usos, prioritariamente para a manutenção da vida e o desenvolvimento de diversas atividades econômicas essenciais também para o sustento humano. Para isso, disponibilidade de água com qualidade é essencial (TUNDISI et al, 2014).

O legislador brasileiro adotou uma governança e gestão adaptativas, quando estabeleceu como diretriz a adequação da gestão de recursos hídricos às diversidades físicas, bióticas, demográficas, econômicas, sociais e culturais das diversas regiões do País, ou seja, é possível termos instrumentos, ferramentas e normas gerais, mas é preciso que verifiquemos como são as condições locais e regionais. Interessante que Ribeiro e Johsson (2018) travaram uma discussão

10 O Convênio de Helsink - Convênio sobre a proteção e uso dos cursos de água transfronteiriços e dos lagos internacionais (elaborado na Finlândia em 1992 e entrando em vigor em 1996) e a Convenção de Nova Iorque de 1997 sobre o uso de água internacionais. 
acerca dos desafios da governança da água e estabeleceram alguns pressupostos que são destacados na literatura pesquisada, dentre os quais estão: governanca justa, resiliência, governanca e capacidade adaptativa e nexo.

A governança justa está ligada com a necessidade de contextualização em face dos problemas locais, especificamente o acesso aos serviços básicos como água e esgoto tratado, o que estaria diretamente entrelaçado com a diminuição das diferenças e a distribuição de água de forma justa, não excludente. A resiliência, capacidade e governança adaptativa são outros termos muito importantes para compreender essas diretrizes que são adaptativas na sua essência, aplicando-se a diversos contextos, principalmente num momento de tantas incertezas climáticas e ambientais. Portanto, uma característica desses termos é justamente a presença da incerteza, ou seja, é preciso preparar os atores para as diversas mudanças que podem vir, e já estão acontecendo, tendo a capacidade de mudar o modelo de governança e sua estrutura conforme as circunstâncias enfrentadas e muitas vezes aprender fazendo constantemente.

O nexo é um fator fundamental para a diretriz da adaptação da política de águas brasileira uma vez que é da essência a intersetorialidade de determinados temas com o tema da água, como, por exemplo energia e alimentação que estão imbricados, não sendo plausível o planejamento isolado, uma vez que o próprio setor agrícola e outros utilizam cerca de $70 \%$ da água, além do potencial contaminante que existe e persiste; e quanto ao setor de energia que utiliza a matriz hídrica renovável e que possui seus impactos nos ecossistemas que compõem as bacias hidrográficas (RIBEIRO e JOHNSSON, 2018; CASTRO et al, 2017). Portanto os temas nexos são fundamentais para o propósito de implementar a PNRH e um Sistema Integrado de Gestão com a finalidade de preservar a qualidade da água e prevenir contaminação.

Outra diretriz que diz respeito à necessária visão sistêmica ou integrativa é que a gestão da água deve estar em compasso com a 
gestão ambiental, sendo duas faces da mesma dimensão. Pensamos e defendemos que ambas gestões não são estanques nem separadas, porém, juntas numa rede de relações fundantes, uma vez que a água é a sustenção da vida, portanto, dos ecossistemas. Na verdade, todo o nosso estudo aqui aportado indica uma governança sistêmica, portanto, integrada, porém existe uma amplitude maior quando se reune gestão ambiental e hídrica, sendo que a primeira, ao que parece, abarca a segunda, uma vez que precisamos perseguir como objetivo dessa governança o equilíbrio entre quantidade e qualidade da água, o que envolve a preservação e proteção da natureza que está em simbiose e que a água acaba por ser o substrato que interliga as diversas formas de vida mas que, porém, depende da proteção equilibrada de outros elementos da natureza.

Podemos perceber de forma mais clara essa integração no âmbito da bacia hidrográfica. Oliveira et al (2017) apontam que a baixa integração entre ambas as dimensões resulta principalmente numa má qualidade da água advinda de seu mau uso. Evidentemente isso gera uma reação em cadeia que interfere em diversos outros setores como a saúde, por exemplo. Fracalanza et al (2010) e Scheibe et al (2019) apresentam um panorama acerca dessa diretriz que não mudou muito, uma vez que a mesma está fundamentada no princípio maior da política de água no Brasil que é a integração.

Outra diretriz para a formulação das ações da política de águas é a articulação do planejamento dos recursos hídricos com os setores usuários e com os planejamentos regional, estadual e nacional, que remete novamente ao princípio da integração e da unicidade da gestão na bacia hidrográfica. Entendemos que a água é uma só e precisa ser gerenciada de forma eficaz com o entrelaçamento dos maiores interessados que são os usuários envolvendo todas as esferas da administração pública e do setor privado. Do contrário não podemos afirmar que ocorre uma governança minimamente eficaz da água.

Portanto, essa diretriz tece inferências em face da dimensão que reputamos mais concreta da governança e gestão que é a articulação setorial, cuja a tarefa não é fácil, primeiramente dada a complexidade 
de atribuições presentes na nossa legislação, segundo a real ausência de integração entre as decisões tomadas, cuja política ordinária e partidária impede muitas vezes de manter esse diálogo ou, em outras, os setores de planejamento não dialogam sobre um recurso comum como a água, sendo muito mais fácil, talvez, atribuir a responsabilidade a determinados setores da gestão.

Silva e Porto (2003) já apontavam em seus estudos que essa constatação de falta de articulação que resultava em baixa integração poderia ser visto cabalmente nas regiões metropolitanas em que esse escopo se ampliava para fora dessa esfera proposta pelo legislador atingindo outros setores que tem influência sobre a governança da água como mobilidade, habitação e a própria gestão pública, o que se complexificava mais ainda levando-se em consideração os múltiplos usos e usuários do sistema. Peixoto et al (2019) aponta que a Gestão Integrada de Recursos Hídricos (GIRH) é fundamental numa perspectiva urbana de prevenção de desastres conectando gestão da água e gestão do solo evitando e mitigando os efeitos das enchentes, por exemplo. Portanto, nessa mesma esteira da integração, a diretriz que estabelece a articulação da gestão de recursos hídricos com a do uso e ocupação do solo, essa é fundamental também, uma vez que a gestão do solo é o cerne para se pensar a gestão e governança da água em espaços urbanos, notadamente naqueles densamente ocupados, como é o caso das nossas grandes regiões metropolitanas. (GARCIA e ROMERO, 2017).

Carneiro et al (2010) já apontavam a fragmentação setorial da nossa administração como sendo reproduzida na gestão integrada da água com a gestão do solo, o que significa na prática a potencialização de desastres urbano ambientais considerando que não houve planejamento integrado real, o que resultou na ocupação indiscriminada do solo trazendo prejuízos, por exemplo, no processo de drenagem nas bacias hidrográficas sobre as quais as cidades e regiões metropolitanas estão localizadas. 
Vieira (2011) indicou em sua pesquisa a prática necessária de integração da gestão da água com o uso e ocupação do solo, começando pelos planos diretores municipais. Esses são documentos fundamentais para o exercício da integração, não só na sua formulação mas na sua aplicação através de ações da gestão e fiscalização pelos órgãos de controle interno e externo, bem como pelo Ministério Público e pelos próprios cidadãos que possuem o instrumento da Ação Civil Pública que já é largamente utilizado em diversas demandas acerca da gestão dos bens ambientais por exemplo.

Nessa direção foi promulgada a Lei n. 13.465/2017, que dispõe sobre a regularização fundiária de áreas urbanas e rurais. Essa lei teve o intuito de buscar uma reorganização mais profunda do espaço urbano e rural diante da realidade caótica de situações irregulares existentes especialmente nas regiões metropolitanas. No texto da política de água, considerando também o saneamento especificamente o esgoto tratado, fica muito clara a necessidade de aplicarmos o princípio da integração concretamente para que haja uma governança que contribua com a qualidade de vida. Mais além da própria lei, é preciso se perguntar porque se ocupa irregularmente um determinado território, pensamos que a hipótese mais provável seja a ausência de planejamento associado com ausência de fiscalização.

As regiões metropolitanas e cidades precisam ser pensadas através da construção de cenários que antevejam dez, vinte, trinta ou mais anos, pois daí poderemos evitar desastres, impermeabilização indevida do solo, fechamento das zonas de recarga de aqüíferos, ocupação das encostas de morro e margens de cursos de água. Isso conjugado com a Lei n. 11.977/2009, permite pensar os espaços urbanos entre o formal e o informal e como inserir-se essa realidade como cidade. Obviamente que as leis n. 10.257/2001 e 13.089/2015, respectivamente estatuto da cidade e estatuto da metrópole devem participar dessa sinergia integrativa de ações para efetivação da política de águas com consequências diretas na melhoria da saúde da população. Na ótica de Figueiredo Júnior e Nunes (2018) esses paradigmas estabelecidos na legislação são fundamentais para pensar 
num espaço urbano sustentável que possa harmonizar os diversos interesses existentes.

A nossa argumentação de uma governança adaptativa necessária e da preponderância do princípio da integração em todo o sistema é reforçada pela última diretriz, qual seja: a integração da gestão das bacias hidrográficas com a dos sistemas estuarinos e zonas costeiras. O sistema estuarino ${ }^{11}$ é a desembocadura de águas de rio profundo no mar, ocorrendo uma mistura do ecossistema de água doce com o de água salgada. E a zona costeira é a faixa litorânea de nosso território. Esse ponto da PNRH torna irreversível a tônica integrativa do sistema, fortalecendo a unidade territorial conhecida como bacia hidrográfica como sendo o locus para implementarmos todas as ações da política de águas, o que gera efeitos em cadeia, interligados, podendo atingir outras regiões, inclusive o ecossistema marinho, como é o exemplo dos desastres de Mariana e Brumadinho, em Minas Gerais.

Barroso et al (2009) apontam a fragilidade e quase inexistência de uma governança e gestão da água entre bacia hidrográfica e o sistema estuarino, o que nos expõe a diversos riscos, uma vez que não se planeja e nem se age de forma conjunta para que não haja prejuízos ao sistema de vida estabelecido em ecosistemas e regiões metropolitanas. Mendes e Loitzenbauer (2014) apresentam evidências da falta de integração baseadas no fato de que o gerenciamento não respeita o funcionamento dos sistemas físicos, utilizando os limites municipais como unidade de gestão.

A gestão de recursos hídricos utiliza como unidade territorial as bacias hidrográficas, mas não considera a influência marinha nas

${ }^{11}$ Um sistema estuarino é uma indentacão costeira com conexão restrita com o oceano, sendo permanentemente aberta ou intermitente. Os sistemas estuarinos podem ser subdivididos em três regiões: a) a zona fluvial de maré: a zona fluvial com ausência de salinidade marinha, porém sujeita à subida e descida do nível do mar; b) a zona de mistura (o estuário propriamente dito): caracterizada pela mistura da massa d'água e por fortes gradientes de propriedades físicas, químicas e biológicas abrangendo desde a zona fluvial de maré até a foz fluvial no mar; e c) a zona de turbidez costeira no mar aberto entre a zona de mistura e o limite oceânico da pluma fluvial durante o auge da maré baixa. (BARROSO et al, 2009, p.14-15). 
partes baixas da bacia, no estuário. Tem-se um conflito entre concepções, considerando que precisamos dialogar com quem conhece a fundo a dinâmica desses ecossistemas e canalizar isso para o texto das leis e para os tomadores de decisão. Isso é relevante também na medida em que incentiva a governança ambiental indo além da governança da água. (TEIXEIRA et al, 2018).

Portanto, não se pode pensar integração levando-se em consideração apenas uma escala, mas múltiplas escalas, claro que isso dificulta a concretização da PNRH principalmente porque nossa zona costeira é extremamente habitada e, certamente, de modo irregular com a exploração do turismo e de outras atividades econômicas. $\mathrm{Na}$ própria lei da PNRH ficou explícita a responsabilidade da União, governo central, em fomentar a articulação com os estados no que fosse recurso comum.

\section{A RELAÇÃo dA ÁGUA COM A SAÚdE}

Água é vida e saúde, e estamos vivenciando atualmente uma pandemia que é decorrência da relação homem e natureza, como atestou o relatório da Organização Mundial de Saúde (WHO, 2019). Sabemos que parte da população não tem acesso à água necessária para sua sobrevivência tão pouco para realizar simples atos de higiene pessoal como lavar as mãos. Segundo Barcellos (2019) a tônica urbana é que se consegue acesso à água sem soleta de esgotos e sem tratamento dos mesmos, por isso é fundamental um olhar ampliado da saúde em relação ao saneamento. Portanto, a governança da água não deve ser apenas apresentar formas de acesso à água e ao saneamento, mas apresentar formas de acesso à água de qualidade, o que representa diretamente saúde, bem como preparação para situações excepcionais como a crise do Covid 19.

Ribeiro (2018) apresenta a ligação entre água e uma política sanitária mínima para manutenção da dignidade humana, destacando que é necessário o Direito se pautar nas orientações científicas e 
técnicas para nortear as decisões do Judiciário e da própria gestão pública no sentido de conseguirmos uma água que gere saúde e não mais doença. Quanto a isso o Supremo Tribunal Federal se pronunciou cabalmente sobre a necessidade imperiosa e cogência das orientações técnicas e científicas de órgãos como a OMS e não cabe discricionariedade nesse campo, ou seja, o gestor não pode escolher pela não aplicação de regras que impõem determinadas condutas, a exemplo do isolamento social, como sendo eficazes para a mitigação ou prevenção de doenças transmissíveis como a Covid 19. (BRASIL, 2020).

No caso da água e do esgotamento existe uma linha tênue entre a saúde e uma política sanitária eficaz. (WANG et al, 2005; CASANOVA et al, 2009; SIDDHARTA et al, 2017; VENTURA, 2020; SILVA et al, 2020). No caso da Covid 19, pesquisas em várias partes do mundo atestaram a presença do vírus no sistema de esgotos, o que alerta para a situação de nossas zonas urbanas e rurais em que ainda encontramos o esgoto correndo ao ar livre sem uma uma coleta apropriada tão pouco tratamento desses resíduos das águas utilizadas.

Sem dúvida que num contexto desses o risco de contaminação deve estar no "radar" do Ministério Público e dos gestores públicos, bem como da comunidade científica. Ainda não há nenhum caso de infecção por via feco-oral, ou seja, pelo contado com o esgoto não tratado ou com fezes, porém, os estudos estão sendo desenvolvidos no sentido de verificar a potencialidade do vírus quando descartado por meio do sistema de esgotamento ou na água não tratada. (ZHANG et $a l, 2020$; GU et al, 2020, HELLER et al, 2020). O vírus não consegue resistir à água tratada com cloro, porém pode ser encontrado nos resíduos sólidos e no esgoto. 


\section{CONSIDERAÇões FINAIS: CHAVES PARA EVITAR OUTRAS CRISES PLANETÁRIAS}

Diante dessas ponderações, entendemos que se não houver um olhar e uma prática de gestão e legislativa no sentido de integrar saneamento, meio ambiente e saúde, estaremos mais vulneráveis a crises pandêmicas como essas e às doenças que já estão no nosso "cardápio" como dengue, Zika e febre amarela, para citar algumas. Dessa forma, a governança adaptativa tem se mostrado o modelo mais adequado para o enfrentamento do contexto local e regional do uso e acesso à água, sendo fundamental a compreensão de que podemos aplicar princípios gerais para todos os modelos, uma espécie de conjunto de diretivas gerais. Porém, é preciso compreender o (s) cenário (s) local e regional como sendo os definidores de um modelo aplicável e que a matriz ecológica ela é indispensável para para fazer essa relação entre saneamento e saúde prosperar.

Não há como pensar uma governança da água que não seja multi ator, ou seja, estamos diante de um grande conjunto de interesses representados pelo setor público, privado e pela sociedade que geralmente são contrários e exercem pressões diferenciadas. Desse modo, as arenas estão postas e precisamos usar de mecanismos que possam aplainar o caminho de modo a promover uma justiça hídrico-ecológica, ou seja, água suficiente e de qualidade para a sustentação da vida e das atividades econômicas que geram desenvolvimento e uma vida saudável.

Não basta universalizar água, é preciso monitorar sua qualidade e coletar $100 \%$ do esgoto e tratar $100 \%$ desse, e um olhar sensível para a população do campo. Só no caso do semiárido brasileiro são quase 11 milhões de habitantes no campo e mais de 50\% não tem nenhuma estrutura de saneamento básico, portanto estão vulneráveis às diversas doenças de veiculação hídrica. (INSA, 2014). É preciso uma 
agenda hídrico-sanitária pós-pandemia que permita a criação de espaços urbano e rurais resilientes ${ }^{12}$.

É preciso ir além de um modelo pontual de governança. Necessitamos de um modelo que seja ecológico, abrangente, que pense a água como uma só água, interligando, integrando e dando uma visão sistêmica do ciclo da água e do ciclo urbano da água com a saúde e o meio ambiente. O modelo de governança nacional é fragmentado, uma vez que coloca de um lado a Política Nacional de Recursos Hídricos e de outro a Política Nacional de Saneamento Básico, quando deveríamos ter um sistema normativo que regulasse a governança da água considerando um ciclo que sofre a intervenção humana, seja na modificação do mesmo, ou na racionalização do uso da água e formação de um ciclo fechado da mesma, num modelo circular em que se capta a água, usa-se e depois reutiliza-se.

É preciso avançar na desetorialização da governança da água, isto implica em modificação da gestão, mantendo $o$ viés descentralizado e participativo, porém adotando uma visão sistêmica, resgatando o valor sócio jurídico e ambiental da bacia hidrográfica como unidade territorial complexa e que tem força jurídica. É necessário dar oportunidade a setores da sociedade civil a participarem da tomada de decisão, bem como do processo de construção do planejamento. Ouvir quem compõe o território da bacia é fundamental para uma compreensão sistêmica que é complementada pelo conhecimento técnico.

Estamos diante de um bem comum que tem como característica recorrente sua escassez, seja pela ausência de mananciais, seja pelo uso excessivo em diversas atividades econômicas, a ação poluidora sobre a água é resultado de externalidades ambientais. Além disso, é preciso considerar que temos um bem valorável, sendo central que ele seja tripartite: econômico, ecológico e social. A governança nacional é descentralizada e fundamentada na participação de diversos setores,

12 Ambientes resistentes e capazes de terem uma recuperação rápida frente às circunstâncias graves e de desastres por exemplo. (SILVA, 2020). 
entretanto, com mudanças recentes na constituição do Conselho Nacional de Recursos Hídricos (CNRH) e no reposicionamento da própria política de gestão da água para o Ministério de Desenvolvimento tendo como resultado um maior distanciamento entre as políticas de meio ambiente e a PNRH. As bacias hidrográficas não devem ser enxergadas como territórios descolados de uma profusão de atividades econômicas, escalas geográficas e administrativo-políticas plurais, sendo preciso redimensionar os planejamentos para uma matriz urbano-ambiental.

Data de Submissão: 02/05/2020

Data de Aprovação: 31/05/2020

Processo de Avaliação: double blind peer review

Editor Geral: Jailton Macena de Araújo

Editor de Área: Fernando Joaquim Ferreira Maia

Assistente Editorial: Matheus Victor Sousa Soares

\section{REFERÊNCIAS}

BARBOZA, E. M. de Q.; KOZICKI, K. Judicialização da política e controle judicial de políticas públicas. Revista Direito GV, [S.l.], v. 8, n. 1, p. 059-085, jan. 2012. ISSN 2317-6172. Disponível em: $<$ http://bibliotecadigital.fgv.br/ojs/index.php/revdireitogv/article/vi ew/23970/22728 >. Acesso em: 01 Mai. 2020.

BARCELLOS, C. Adaptação, vulnerabilidades e saúde nas metrópoles. In TORRES, P. et al (Org). Governança e Planejamento ambiental: adaptação de políticas públicas na macrometrópole paulista. Rio de Janeiro: Letra Capital, 2019.

BARREIRO, G. S. de S.; FURTADO, R. P. M. Inserindo a judicialização no ciclo de políticas públicas. Rev. Adm. Pública, Rio de Janeiro , v. 49, n. 2, p. 293-314, Apr. 2015. Available from

$<$ http://www.scielo.br/scielo.php?script=sci_arttext\&pid=So034- 
Governança Da Água E Os Elementos Essenciais Para Prevenir Crises...

$76122015000200293 \& \operatorname{lng}=\mathrm{en} \& \mathrm{nrm}=\mathrm{iso}>$. access on 02 May 2020. https://doi.org/10.1590/0034-7612126144, Acesso, 1 de maio de 2020.

BARROSO, G. F.; ZAMBONI, A.; NICOLODI, J. L. Gestão Integrada de Bacias Hidrográficas e Zonas Costeiras no Brasil: Implicações para a Região Hidrográfica Amazônica. Revista da Gestão Costeira Integrada 9(2):9-32, 2009.

BRAGA, L. M. M.; RANDO, A. S.; FERRÃO, A. M. de A. A Governança das Águas no Brasil: uma análise sobre o papel da universidade em redes e observatórios. Redes (St. Cruz Sul, Online), v.25 , n.1 , p. 363-380, janeiro-abril, 2020.

BRAGA, L.M.M.; ARGOLLO FERRÃO, A.M. A gestão dos recursos hídricos na França e no Brasil com foco nas bacias hidrográficas e seus sistemas territoriais. Labor \& Engenho, Campinas [SP] Brasil, v.9, n.4, p19-33, out./dez. 2015. http://www.conpadre.org

BRASIL. Supremo Tribunal Federal. Medida Cautelar na Ação Direta de Inconstitucionalidade 6.341, DF. Requerente: Partido Democrático Trabalhista. Brasília, 24 de março de 2020.

CAPELLA, A. C. N.. Formulação de Políticas. Brasília: Enap, 2018.

CARINI, L.; DE MORAIS, F. S. Governança Ética Para Construção De Confiança Em Sistemas De Inteligência Artificial. Prim Facie, v. 19, n. 40, 19 dez. 2019.

CARLI, A. A. de. As dimensões dos direitos das águas. Revista de Direito Administrativo, Rio de Janeiro, v. 276, p. 77-107, set./dez. 2017.

CARLI, A. A. de; VASCONCELOS, T. F. de. Saneamento básico e água potável: a correlação necessária na seara da proteção dos direitos da natureza. In LEITE, J.R.M., PERALTA, C. E., CARLI, A. A. de. (Orgs.). Agua y Saneamiento Básico en el Siglo XXI: Brasil y Costa Rica. San Jose: Universidad de Costa Rica, 2018.

CARNEIRO, P. R. F. ; CARDOSO, A. L.; ZAMPRONIO, G.

B. and MARTINGIL, M. de C. A gestão integrada de recursos hídricos e do uso do solo em bacias urbano-metropolitanas: o controle de inundações na bacia dos rios Iguaçu/Sarapuí, na Baixada Fluminense. Ambient. soc., Campinas, v. 13, n. 1, p. 29-49, June 2010. Available from $<$ http://www.scielo.br/scielo.php?script=sci_arttext\&pid=S1414753X2010000100003\&lng $=$ en\&nrm $=$ iso $>$. Access on 17 Mar. 2020. https://doi.org/10.1590/S1414753X2010000100003.

CASANOVA, L., RUTALA, W. A., WEBER, D. J., \& SOBSEY, M. D. Survival of surrogate coronaviruses in water. Water research, 43(7), 1893-1898, 2009.

CASTELLANOS, C. E. Q. Gobernanza y teoría de las organizaciones. Perfiles Latinoamericanos, 25(50), 2017, pp. 39-57. 
CASTRO, J. E.; ALVES OLIVEIRA SILVA, J. I.; CUNHA, L. H. Os desafios da "cidadania" hídrica na América Latina: conflitos, Estado e democracia. Prim Facie, v. 16, n. 32, p. 01-39, 14 ago. 2017.

CAVEDON-CAPDEVILLE, F. S. Jurisprudência ecologizada nas Cortes de Direitos Humanos: contribuições para a ecologização dos direitos humanos. CAVEDON-CAPDEVILLE, F. S.; LEITE, J. R. M.; DAROS, L. F.; MELO, M. E.; AYALA, P. A.; SILVEIRA, P. G. A Ecologização do Direito Ambiental Vigente: rupturas necessárias. Rio de Janeiro: Lumen Juris, 2018. p. 185-221.

CUNHA, B. P. da; SILVA, J. I. . O. and GOMES, I. R. F. D.. Políticas Públicas Ambientais: judicialização e ativismo judiciário. Rev. Fac.

Der. [online]. 2017, n.42, pp.153-179. ISSN 0797-

8316. http://dx.doi.org/10.22187/rfd201718.

DUNRISE, A. Manipulating Social Tensions: Collibration as an Alternative Mode of Government Intervention. MPIFG Discussion Paper 93/7,Max-Planck-Institut für Gesellschaftsforschung, 1993.

FERRAÇO, A. A. G. A insuficiência de integração na gestão nacional dos recursos hídricos brasileiros como óbice estrutura ao desenvolvimento sustentável. Dissertação de Mestrado. Programa de Pós-Graduação em Direito. Universidade de Brasília. 2019.

FIGUEIREDO JUNIOR, C. M.; NUNES, M. A. da C. A. Regularização fundiária urbana: estudo de caso do bairro nova conquista, São Mateus ES. Revista de Direito da Cidade, [S.1.], v. 10, n. 2, p. 887-916, maio 2018. ISSN 2317-7721. Disponível em: <https://www.epublicacoes.uerj.br/index.php/rdc/article/view/31769>. Acesso em: 10 abr. 2020. doi:https://doi.org/10.12957/rdc.2018.31769.

FRACALANZA, A. P.; CAMPOS, V. N. de O. Governança das águas no Brasil: conflitos pela apropriação da água e a busca da integração como consenso. Ambient. soc., Campinas , v. 13, n. 2, p. 365382, Dec. 2010. Available from $<$ http://www.scielo.br/scielo.php?script=sci_arttext\&pid=S1414753X2010000200010\&lng $=$ en\&nrm $=$ iso $>$. Access on 17 Mar. 2020. https://doi.org/10.1590/S1414753X2010000200010.

FREY, K.; RAMOS, R. C. F.; MORAES, E.; SÁ, G. J. de G. Desafios contemporâneos para governança democrática da água: o caso da macrometrópole Paulista. Anais do XVIII Enanpur, maio de 2019, Natal, Rio Grande do Norte.

GARCIA, J. R.; ROMEIRO, A. R. Gestão Integrada dos recursos hídricos: a experiência de Nova Iorque. In MESSIAS, A. S. (Org.). Rios urbanos limpos : possibilidades e desafios. Recife : FASA, 2017.

GLOBAL WATER PARTNERSHIP. Gobernabilidad Efectiva del Agua. Comité Técnico de GWP, 2006. 
Governança Da Água E Os Elementos Essenciais Para Prevenir Crises...

GLOBAL WATER PARTNERSHIP. Guía para la aplicación de la Gestión Integrada del Recurso Hídrico (GIRH) a nivel municipal. Tegucigalpa, M.D.C, Honduras Diciembre 2013.

GOMIDE, J. E. e SILVA, A. C. O surgimento da expressão "governance", governança e governarça ambiental. In Revista de Ciências Gerenciais, Vol. XIII, No. 18, Ano 2009.

HELLER, L.; MOTA, C. R.; GRECO, D. B. COVID-19 faecal-oral transmission: Are we asking the right questions? Science of the Total Environment, v. 729, p. 1-3, 2020.

JACOBI, P. R.; FRACALANZA, A. P.; EMPINOTTI, V. Governanca da água no contexto da escassez hídrica. São Paulo: IEE-USP,UFABC e GovAmb, 2017.

JACOBI, P.R., DE STEFANO, L., LÓPEZ-GUNN, E., SOLANES, M., DELACÁMARA, G., MARÍN, G., EMBID, A., EMPINOTTI, V., BLANCO, E., DONOSO, G., RICA, M. URIBE, N., JIMÉNEZ, A. Reforming water governance structures. In Willaarts, B.A., Garrido, A., Llamas, M.R. (Eds.), Water for Food and Wellbeing in Latin America and the Caribbean. Social and Environmental Implications for a Globalized Economy. Routledge, Oxon and New York, p. 286-315, 2014.

KATSAMUNSKA, P. The Concept of Governance and Public Governance Theories. Economic Alternatives, Issue 2, 2016.

KENNETH, P. Governance, globalization and public policy. Great Britain: Edward Elgar Publishing Limited, 2008.

LEITE,J. R. M.; SILVA, J. I. A. O. A releitura ecológica da política de água: bacia hidrográfica e sua relevância jurídica. Revista de Direito Ambiental, v. 94, abril-jun, 2019.

MARK, G.; HOOGHE, L. Contrasting Visions of Multi-level Governance. BACHE, I.; FLINDERS, M. Multi-level Governance. Oxford, 2004.

MEIER, K. J. e O’TOOLE L. J. Public management: organizations, governance, and performance. New York: Cambrige, 2011.

MENDES, C. A. B.; LOITZENBAUER, E. A Faixa Terrestre da Zona Costeira e os Recursos Hídricos na Região Hidrográfica do Atlântico Sul, Brasil. Revista de Gestão Costeira Integrada, 14(1):81-94, 2014.

OLIVEIRA, R. C. de; LIMA, P. V. P. S. e SOUSA, R. P. Gestão Ambiental e Gestão dos Recursos Hídricos no contexto do uso e ocupação do solo nos municípios. Gestão \& Regionalidade - Vol. 33 - No 97 - jan-abr/2017. 
OSTROM, E. Coping with tragedies of the Commons. Annu. Rev.

Polit. Sci. 1999. 2:493-535.

OSTROM, E.. Beyond Markets and States: polyjcentric governance of complex economic systems. American Economic Review, 100, 641642, 2010.

OSTROM, E.. Understanding Institutional Diversity. Printeton: Princeton University, 2005.

OSTROM, E.; GARDNER, R. e WALKER, J. Rules, Games and Common Pool Resources. United States of America: The University Michigan Press, 1994.

PACHECO-VEGA, R. Ostrom y la gobernanza del agua en México. Revista Mexicana de Sociología 76, núm. especial (septiembre, 2014): 137-166.

PAIVA SOBRINHO, R.; GARCIA, J. R.; MAIA, A. G.; ROMEIRO, A. R. Inovação na governança da água. Revista Brasileira de Inovação, v. 18, n. 1, p. 157-176, 23 jul. 2019.

PEIXOTO, F. da S.; RODRIGUES, J. P. B.;ALBUQUERQUE, P. I. de M. Gestão integrada dos recursos hídricos e a problemática das inundações urbanas. Geografia (Londrina), v. 28. n. 1. pp. 187 - 206, fevereiro/2019.

PEREIRA, R. R. Governança no Setor Público: origem, teorias, modalidades e aplicações. Revista do TCU, n. 122, 2011.

PIRES, R., CAVALCANTE P. Governança Pública: Construção de capacidades para a efetividade da ação governamental. Nota Técnica IPEA, Brasília, n. 24, julho de 2018, Diretoria de Estudos e Políticas do Estado, das Instituicões e da Democracia, disponível em: http://repositorio.ipea.gov.br/bitstream/11058/8581/1/NT_24_Diest_Gov ernança.pdf.

RAADSCHELDERS, J. C. N.; VIGODA-GADOT, E.; KISNER, M. Global Dimensions of Public Administration and Governante. United States of America: John Wiley \& Sons, Inc., 2015.

RAMALHO, A. M. Governança corporativa em startups. Revista de Direito, Governança e Novas Tecnologias, Belém, v. 5, n. 2, p. 74 - 91, Jul/Dez. 2019.

RIBEIRO, N. B.; JOHNSSON, R. M. F. Discussões dobre governança da água: tendências e caminhos comuns. Ambient. soc., São Paulo , v. 21, e01252, 2018. Available from <http://www.scielo.br/scielo.php?script=sci_arttext\&pid=S1414$753 \mathrm{X} 2018000100314 \& \operatorname{lng}=\mathrm{en} \& \mathrm{nrm}=\mathrm{iso}>$. Access on 17 Mar. 2020. Epub Oct o8, 2018. https://doi.org/10.1590/1809-4422asoc0125r2vu18l1ao. 
Governança Da Água E Os Elementos Essenciais Para Prevenir Crises...

RIBEIRO, W. A. O direito à água e saúde pública. Revista de Direito

Sanitário, v. 18, n. 3, p. 94-103, 22 mar. 2018.

RODRIGUES, V.; BERNARDO, E. Turismo em Cabo Verde, governação e governança. PASOS. Revista de Turismo y Patrimonio Cultural, V. 18 N. ${ }^{\circ}$ 1, p. 27-38. Enero-Marzo 2020.

https://doi.org/10.25145/j.pasos.2020.18.002.

RUSSEL, M. B.; SCOTT, C. Putting Investors First: Real Solutions for Better Corporate Governance. Bloomberg, 2003.

SCHEIBE, L. F.; TRINDADE, L. DE L. Gestão das água: limitações e contribuições na atuação dos comitês de bacias hidrográficas brasileiros. Ambient. soc., São Paulo, v. 22, e02672, 2019. Disponível em <http://www.scielo.br/scielo.php?script=sci_arttext\&pid=S1414753X2019000100310\&lng $=$ pt\&nrm $=$ iso $>$. Acesso

em 10 abr. 2020. Epub 26-Ago2019. https://doi.org/10.1590/18094422asoc20160267r2vu2019l2ao.

SEIXAS, C. S. et al. Governança ambiental no Brasil: rumo aos objetivos do desenvolvimento sustentável (ODS)?. Cadernos Gestão Pública e Cidadania, [S.1.], v. 25, n. 81, mai. 2020. ISSN 2236-5710. Disponível em:

<http://bibliotecadigital.fgv.br/ojs/index.php/cgpc/article/view/814 04>. Acesso em: 25 Mai. 2020.

doi:http://dx.doi.org/10.1266o/cgpc.v25n81.81404.

SIDDHARTA, A., PFAENDER, S., VIELLE, N. J., DIJKMAN, R., FRIESLAND, M., BECKER, B., ... \& BRILL, F. H. Virucidal activity of WHO-recommended formulations against enveloped viruses including Zika, Ebola and emerging Coronaviruses. The Journal of infectious diseases, 2017. Disponível em:

https://academic.oup.com/jid/article/215/6/902/2965582. Acesso em 19 de maio de 2020.

SILVA, E. M. da; ANDRADE, T. de S.; SAEGER, M. M. de M. T. Judicialização de políticas públicas: uma análise da intervenção do Poder Judiciário na elaboração, implantação e execução de políticas públicas à luz da jurisprudência do STF e do STJ. Cadernos de Pesquisa Interdisciplinar em Ciências Humanas, Florianópolis, v. 16, n. 109, p. 75-95, abr. 2017. ISSN 1984-8951. Disponível em: $<$ https://periodicos.ufsc.br/index.php/cadernosdepesquisa/article/v iew/1984-8951.2015v16n109p75>. Acesso em: 01 maio 2020. doi:https://doi.org/10.5007/1984-8951.2015v16n109p75.

SILVA, J. I. A. O . Segurança Hídrica Ecológica: fundamentos para um conceito jurídico. Tese de Doutorado. Program de Pós-graduação em Ciências Jurídicas. Universidade Federal da Paraíba, Brasil, 2020. 
SILVA, J. I. A. O.; LEITE, J. R. M. Proteção e Governança da água e o Estado de Direito Ecológico. Revista Internacional de Direito Ambiental, RIDA, v. 22, jan-abr, 2019.

SILVA, J. I. A. O.; SOUZA, C. M. de; BARBOSA, J. L. A.. "Zika virus" e desenvolvimento regional: linhas preliminares de análise. Revista

Brasileira de Desenvolvimento Regional, Blumenau, v. 8, n. 1, p. 2754, maio 2020. ISSN 2317-5443. Disponível em:

<https://proxy.furb.br/ojs/index.php/rbdr/article/view/8590>. Acesso em: 23 maio 2020. doi:http://dx.doi.org/10.7867/23175443.2020v8n1p27-54.

SILVA, R. T.; PORTO, M. F. do A. Gestão urbana e gestão das águas: caminhos da integração. Estud. av., São Paulo, v. 17, n. 47, p. 129145, Apr. 2003 . Available from<http://www.scielo.br/scielo.php?script=sci_arttext\&pid=So10 3-40142003000100007\&lng $=$ en\&nrm $=$ iso $>$. access on 10 Apr. 2020. https://doi.org/10.1590/So10340142003000100007.

SWYNGEDOUW, E. The Political Economy and Political Ecology of the Hydro-Social Cycle. Journal of Comtemporary Water Research \& Education, Issue 142, 56-60, august, 2009.

TEIXEIRA, D. M.; ALBUQUERQUE, N. M. A Participação Popular na Governança da Água como Reforço à Cidadania Ambiental nas Democracias da América Latina. Prim Facie, v. 17, n. 34, p. 01-29, 13 jul. 2018.

TOVAR, L. A. R.; FLORES, M. T. e VILCHIS, F. L. La gobernanza. Conceptos, tipos, e indicadores internacionales: Los retos para México. 2015. México: Alta Impresión S.A, 2015.

TUNDISI, J. G. (Coord.) Recursos hídricos no Brasil: problemas, desafios e estratégias para o futuro. Rio de Janeiro: Academia Brasileira de Ciências, 2014.

UNDP. Governance for Sustainable Human Development, A UNDP Policy Document. UNDP, New York, 1997.

UNESCO. World Water Development Report. Oxford, 2006.

UNITED NATIONS CHILDREN'S FUND (UNICEF). Progress on Drinking Water, Sanitation and Hygiene: 2017 Update and SDG Baselines. Geneva: World Health Organization (WHO) and the United Nations Children's Fund (UNICEF), 2017.

UNITED NATIONS ENVIRONMENT PROGRAMME. Environmental Rule of Law, first Global Report. Nairobi, 2019.

UNITED NATIONS ENVIRONMENT PROGRAMME. Environmental Rule of Law, first Global Report. Nairobi, 2019. 
Governança Da Água E Os Elementos Essenciais Para Prevenir Crises...

VENTURA, D. de F. L. et al. Desafios da pandemia de COVID-19: por uma agenda brasileira de pesquisa em saúde global e sustentabilidade. Cad.

Saúde Pública, Rio de Janeiro, v. 36, n. 4, eooo40620, Mar. 2020.

Disponível em: http://cadernos.ensp.fiocruz.br/csp/artigo/1023/desafiosda-pandemia-de-covid-19-por-uma-agenda-brasileira-de-pesquisa-emsade-global-e-sustentabilidade. acessos em 27 Abr. 2020.

http://dx.doi.org/10.1590/0102-311X00040620.

VIEIRA, T. V. Os recursos hídricos e os planos diretores municipais na bacia do Rio Itajaí-Açu. Dissertação de Mestrado. Programa de Pós-Graduação em Geografia. Universidade Federal de Santa Catarina. 2011.

WANG, X. W., Li, J., GUO, T., ZHEN, B., KONG, Q., Yi, B., ... \& ZHU, X. Concentration and detection of SARS coronavirus in sewage from Xiao Tang Shan Hospital and the 309th Hospital of the Chinese People's

Liberation Army. Water science and technology, 52(8), 213-221, 2005.

https://iwaponline.com/wst/article/52/8/213/11065/Concentrationand-detection-of-SARS-coronavirus-in

WORLD HEALTH ORGANIZATION. Report of the WHO-China Joint Mission on Coronavirus Disease 2019 (COVID-19). Disponível https://www.who.int/docs/default-source/coronaviruse/who-chinajoint-mission-on-covid-19-final-report.pdf, p. 08. Acesso 20/05/20.

ZHANG, J., WANG, S., \& XUE, Y. Fecal specimen diagnosis 2019 Novel Coronavirus-Infected Pneumonia. Journal of Medical Virology, 2020, v. 1. Disponível em:

https://onlinelibrary.wiley.com/doi/full/10.1002/jmv.25742. Acesso em 19 de maio de 2020. 


\title{
Water Governance And The Essential Elements To Prevent Planetary Crises: The Brazilian Case
}

\author{
José Irivaldo Alves Oliveira Silva
}

\begin{abstract}
Covid 19 places on the planetary agenda our ability to deal articulately with the systemic problems that we have as environment and, especially, water. Thus, the following question worries us: how will we deal with water and environmental issues in the post pandemic using governance principles based on an ecological matrix? We want to think about a more pragmatic approach in order to reflect on a perspective for the coming decades and that we may be surprised by new pandemics but being better prepared. Therefore, through contemporary and classical bibliographic analysis, in addition to documentary studies and legislation on water governance, we conducted research that resulted in this essay. Therefore, we could see that a paradigm shift is possible, however, this will only be feasible with an adaptive governance model that is based on the participation of all the sectors involved and decision making based on an ecological matrix.
\end{abstract}

Keywords: Pandemic. Sanitation. Governance. Water.

DOI: https://doi.org/10.22478/ufpb.1678-2593.2021v2on44.52261

Conteúdo sob licença Creative Commons: Attribuition-NonCommercial-NoDerivative 4.o International (CC BY-NC-ND 4.0)

(cc) $\mathrm{BY}-\mathrm{NC}-\mathrm{ND}$ 